\title{
Erratum to: The Influence of the Appendiceal Base Diameter on Appendix Stump Closure in Laparoscopic Appendectomy
}

\author{
Samir Delibegović ${ }^{1,2} \cdot$ Zlatan Mehmedović $^{1}$
}

Published online: 14 September 2016

(C) Société Internationale de Chirurgie 2016

\section{Erratum to: World J Surg \\ DOI 10.1007/s00268-016-3564-4}

In Discussion section, fifth paragraph, of the original article, the corrected sentence is as follows:

The size of the tip of the appendix was up to $28.68 \mathrm{~mm}$, which should not affect how the appendiceal stump is closed.

The online version of the original article can be found under doi:10.1007/s00268-016-3564-4.

Samir Delibegović

delibegovic.samir@gmail.com

1 Department of Colorectal Surgery, Clinic for Surgery, University Clinical Centre, Tuzla, Bosnia and Herzegovina

2 Faculty of Medicine, University of Tuzla, Tuzla, Bosnia and Herzegovina 